\title{
PERCEPTION AND ATTITUDE OF HEALTH-CARE PERSONNEL REGARDING THE CONCEPT OF INTEGRATION IN NURSING
}

\author{
NEELAM D PATIL, VAISHALI R MOHITE, MANISHA C GHOLAP, MAHESH CHENDAKE*
}

Department of Medical Surgical Nursing, Krishna Institute of Nursing Sciences, Karad, Maharashtra, India. Email: maheshchendake@rediffmail.com

Received: 01 September 2016, Revised and Accepted: 09 September 2016

\section{ABSTRACT}

Objectives: To assess the perception of health-care personnel regarding the concept of integration in nursing, to assess the attitude of health-care personnel toward the concept of integration in nursing, and to determine the association of perception and attitude toward the concept of integration in nursing with selected socio-demographic variables.

Methods: Research approach adopted was descriptive survey approach. Population were 159 health-care personnel's working at various hospitals and institutions in Maharashtra. Purposive sampling technique was used. Data were collected using structured rating scale, which consisted of 3 sections. Section 1 comprising demographic data, Sections 2 and 3 consisted 10 questions to assess the perception and attitude of health-care personnel. Tool was developed pretesting and reliability of the rating scale was done.

Results: Findings of the study showed that majority 118 (74.21\%) of respondents had low perception, 41 (25.78\%) had medium perception, and none of respondents had high perception regarding the concept of integration. Classification of respondents based on the levels of attitude, the $79(49.68 \%)$ had unfavorable attitude, 75 (47.16\%) had moderately favorable attitude, and 5 (3.14\%) had favorable attitude.

Conclusions: As the result shows that there is medium to low level of perception between the health-care personnel regarding the concept of integration and the attitude is also unfavorable, there is need to find out the barriers of integration in nursing profession.

Keywords: Perception, Attitude, Integration, Health-care personnel.

(C) 2016 The Authors. Published by Innovare Academic Sciences Pvt Ltd. This is an open access article under the CC BY license (http://creativecommons. org/licenses/by/4. 0/) DOI: http://dx.doi.org/10.22159/ajpcr.2016.v9s3.14996

\section{INTRODUCTION}

The nursing profession is faced with increasingly complex health-care issues driven by technological and medical advancements, an aging population, increased numbers of people living with chronic disease, and spiraling costs. Collaborative partnerships between educational institutions and service agencies have been viewed as one way to provide research which ensures an evolving health-care system with comprehensive and coordinated services that are evidence based, costeffective and improve health-care outcomes

Collaboration is a substantive idea repeatedly discussed in healthcare circles. Although the benefits are well validated, collaboration is seldom practiced. The lack of a shared definition is one barrier In addition, the complexity of collaboration and the skills required to facilitate the process are formidable. Much of the literature on collaboration describes what it should look like as an outcome, but little is written describing how to approach the developmental process of collaboration. Many researchers have validated the benefits of collaboration to include improved patient outcomes, reduced length of stay, cost savings, increased nursing job satisfaction and retention, and improved teamwork. The focus on benefits of collaboration could lead one to think that collaboration is a favorite approach to providing patient care, leading organizations, educating future health professionals, and conducting health-care research. Contextual elements that influence the formation of collaboration include time status, organizational values, collaborating participants, and type of problem [1]

\section{Objectives of the study}

1. To assess the perception of health-care personnel regarding the concept of integration in nursing.
2. To assess the attitude of health-care personnel toward the concept of integration in nursing.

3. To determine the association of perception and attitude toward the concept of integration in nursing with selected socio-demographic variables.

\section{METHODS}

The research approach adopted for the study was descriptive survey approach. The population selected for the study were 159 females and males health-care personnel's working at various hospitals and institutions in Maharashtra. The study samples were selected using purposive sampling technique. The data were collected using structured rating scale, which consisted of three sections. Section 1 comprising demographic data; Section 2 consisted 10 questions to assess the perception of health-care personnel regarding the concept of integration in nursing; Section 3 consisted 10 questions to assess the attitude of health-care personnel regarding the concept of integration in nursing. Development of the tool involved steps of test construction that is preparing the blueprint, selection of items, content validation, and establishment of reliability. Content validity of the rating scale was done, and modifications were done according to the suggestions given by the experts. Pretesting and reliability of the rating scale was done. The reliability coefficient was found and it was found to be acceptable.

\section{Inclusion criteria}

The health-care personnel working in selected institutes of Maharashtra. In the present study, health-care personnel are graduate staff nurses, clinical instructor working in teaching side, and clinical instructor working in clinical side. 
Exclusion criteria

1. Health-care personnel are who are not willing to participate in the study.

2. Diploma staff nurses are excluded from the study.

3. Health-care personnel who are not present at the time of data collection.

\section{RESULTS AND DATA ANALYSIS}

Findings of the study showed that the majority $118(74.21 \%)$ of respondents had low perception, 41 (25.78\%) had medium perception,

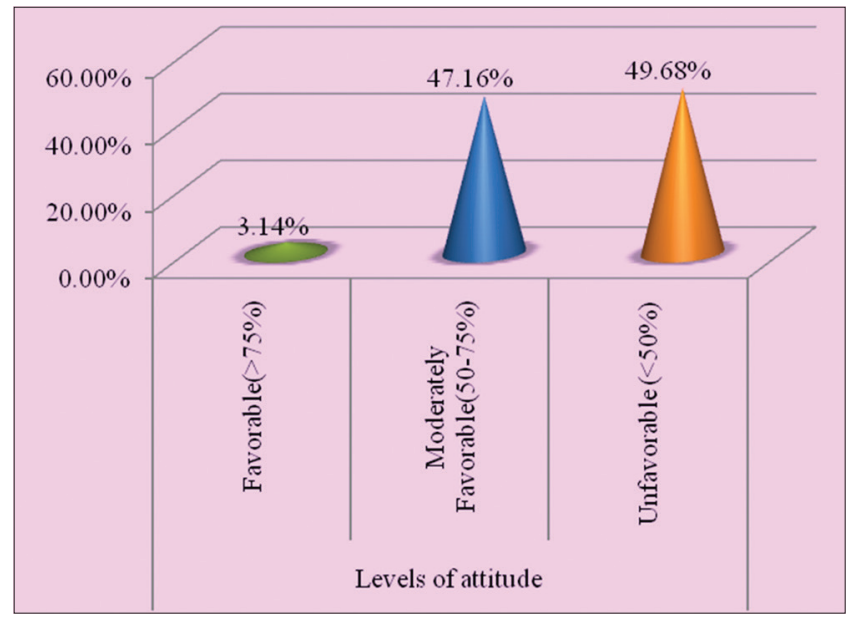

Graph 1: Bar diagram depicting percentage distribution of health-care personnel's attitude level regarding the concept of integration

Table 1: Distribution of health-care personnel perception level regarding the concept of integration $(n=159)$

\begin{tabular}{lll}
\hline Level of perception & Scores \% & F (\%) \\
\hline High perception (score above 37$)$ & $>75$ & $00(00)$ \\
Medium perception (score 25-37) & $50-75$ & $41(25.78)$ \\
Low perception (score $<25)$ & $<50$ & $118(74.21)$ \\
\hline
\end{tabular}

and none of respondents had high perception regarding the concept of integration. Classification of respondents based on the levels of attitude, 79 (49.68\%) had unfavorable attitude, 75 (47.16\%) had moderately favorable attitude, and 5 (3.14\%) had favorable attitude.

None of the demographic variables has shown a significant association with levels of perception. There was a significant association between gender, designation, and place of residence with attitude of health-care personnel's.

Table 1 describes the classification of respondents on levels of perception, $118(74.21 \%)$ of health-care personnel were had low perception, $41(25.78 \%)$ were had medium perception, and none of the respondents had high perception.

Graph 1 describes the classification of respondents based on the levels of attitude, 79 (49.68\%) had unfavorable attitude, $75(47.16 \%)$ had moderately favorable attitude, and 5 (3.14\%) had favorable attitude.

Table 2 describes the association between the selected demographic variables with levels of attitude. Chi-square test was used for computing the association. Computed Chi-square value has shown a significant association among the gender $\left(8.85, \mathrm{df}=1, \mathrm{~S}^{*} \mathrm{p}<0.05\right)$, designation (15.63, $\left.\mathrm{df}=2, \mathrm{~S}^{*}, \mathrm{p}<0.05\right)$, and place of residence $\left(17.98, \mathrm{df}=2, \mathrm{~S}^{*}\right.$ at $\mathrm{p}<0.05$ ), and other demographic variables did not show any association with the levels of attitude.

\section{Major findings}

1. Majority of health-care personnel that is 118 (74.21\%) had very low perception regarding the concept of integration.

2. Majority of the respondents $79(49.68 \%)$ have unfavorable attitude toward the concept of integration in nursing.

\section{DISCUSSION}

In the present study, classification of respondents based on the levels of attitude, $75(47.16 \%)$ had moderately favorable attitude. These findings are little consistence with the mention study. A study conducted in three central government hospitals/schools of nursing in Delhi on nursing personnel having minimum graduation degree in nursing to assess the opinion of the nursing personnel in education, administration, and service toward dual role as nurse educator and

Table 2: Describes the Chi-square association between the attitudes of health-care personnel with socio-demographic variables

\begin{tabular}{|c|c|c|c|c|c|}
\hline \multirow[t]{3}{*}{ Variables } & \multirow[t]{3}{*}{ Categories } & \multirow[t]{3}{*}{$\mathbf{F}$} & \multicolumn{2}{|l|}{ n (\%) } & \multirow[t]{3}{*}{ Chi-square } \\
\hline & & & \multicolumn{2}{|c|}{ Level of attitude } & \\
\hline & & & $<$ Median 25 & $\geq$ Median 25 & \\
\hline \multirow[t]{2}{*}{ Gender } & Male & 18 & $3(16.67)$ & $15(83.33)$ & \multirow[t]{2}{*}{$8.85, \mathrm{df}=1, \mathrm{~S}^{*} \mathrm{p}<0.05(3.89)$} \\
\hline & Female & 141 & $76(53.90)$ & $65(46.10)$ & \\
\hline \multirow[t]{2}{*}{ Education } & Degree & 157 & $79(50.32)$ & 78 (49.68) & \multirow[t]{2}{*}{$2.00, \mathrm{df}=1, \mathrm{NS}$} \\
\hline & Post-graduate & 02 & $0(0.00)$ & $2(100.00)$ & \\
\hline \multirow{2}{*}{ Designation } & Clinical instructor- teaching side & 30 & $6(20.00)$ & $24(80.00)$ & \multirow{2}{*}{$15.63, \mathrm{df}=2, \mathrm{~S}^{*}, \mathrm{p}<0.05$ (5.99) } \\
\hline & Clinical instructor- clinical side & 02 & $0(0.00)$ & $2(100.00)$ & \\
\hline \multirow[t]{3}{*}{ Monthly income } & Below Rs 20,000 & 149 & $73(48.99)$ & $76(51.01)$ & \multirow[t]{3}{*}{$4.05, \mathrm{df}=2, \mathrm{NS}$} \\
\hline & Rs $20,001-30,000$ & 08 & $6(75.00)$ & $2(25.00)$ & \\
\hline & Above Rs 30,001 & 02 & $0(0.00)$ & $2(100.00)$ & \\
\hline \multirow[t]{3}{*}{ Religion } & Hindu & 85 & $36(42.35)$ & $49(57.65)$ & \multirow[t]{3}{*}{$5.45, \mathrm{df}=2, \mathrm{NS}$} \\
\hline & Muslim & 08 & $3(37.50)$ & $5(62.50)$ & \\
\hline & Christian & 66 & $40(60.61)$ & $26(39.39)$ & \\
\hline \multirow[t]{4}{*}{ Marital status } & Married & 02 & $0(0.00)$ & $2(100.00)$ & \multirow[t]{4}{*}{$2.00, \mathrm{df}=1, \mathrm{NS}$} \\
\hline & Single & 157 & $79(50.32)$ & 78 (49.68) & \\
\hline & Widow & 00 & 0 & & \\
\hline & Divorced & 00 & 0 & & \\
\hline \multirow[t]{3}{*}{ Place of residence } & Urban & 113 & $68(60.18)$ & $45(39.82)$ & \multirow[t]{3}{*}{$17.98, \mathrm{df}=2, \mathrm{~S}, \mathrm{p}<0.05$ (5.99) } \\
\hline & Rural & 23 & $4(17.39)$ & $19(82.61)$ & \\
\hline & Semi urban & 23 & $7(30.43)$ & $16(69.57)$ & \\
\hline
\end{tabular}


as nurse practitioner. According to the study, the majority of nursing personnel $92.4 \%$ expressed agreement for the dual role [2].

\section{CONCLUSION}

As the result shows that there is medium to low level of perception between the health-care personnel regarding the concept of integration and the attitude is also unfavorable, there is need to find out the barriers of integration in nursing so that it is possible for the liaison of nursing education and nursing services so that the collaboration can bring out the benefit outcome in the quality care.

\section{REFERENCES}

1. Malloy C, Donahue FT. Collaboration projects between nursing education and service. Nurse Educ Today 2004;19(6):368-77.

2. Balachandran R. Dual role of nurses as educators and practitioners Nurs J India 2008;99(10):231-3. 